\title{
Current Trends of Immunotherapy in the Treatment of Cutaneous Melanoma: A Review
}

Piyu Parth Naik ic

Received: June 21, 2021 / Accepted: July 17, 2021 / Published online: August 2, 2021

(C) The Author(s) 2021

\begin{abstract}
Cutaneous melanoma remains a severe public health threat, with annual incidence increasing slowly but steadily over 4 decades. While earlystage melanomas can typically be treated with complete surgical excision with favorable results, the development of metastatic cancer, which is related to a lower survival rate, is linked to the primary tumor's rising stage and other high-risk features. Even though the first discoveries of an immunological anti-tumor response were published about a century ago, immunotherapy has only been a feasible therapeutic option for cutaneous melanoma in the last 30 years. Nonetheless, for the treatment of various cancers, including metastatic melanoma, the area of cancer immunotherapy has made significant progress in the last decade. As a result, melanoma continues to be the subject of several preclinical and clinical investigations to further understand cancer immunobiology and test different tumor immunotherapies. Immunotherapy's resistance to radiation and cytotoxic chemotherapy is one of its most distinguishing features. Furthermore, the discovery of biomarkers will aid in patient stratification and management during immunotherapy treatment. In this article, we discuss current
\end{abstract}

\section{P. P. Naik (ه)}

Department of Dermatology, Saudi German

Hospitals and Clinics, Dubai, United Arab Emirates

e-mail: drpiyu85@gmail.com knowledge and recent developments in immunemediated therapy of melanoma.

Keywords: Immunotherapy; Melanoma; Ipilimumab

\section{Key Summary Points}

Cutaneous melanoma remains a severe public health threat, with annual incidence increasing slowly but steadily over 4 decades. Immunotherapy has only been a feasible therapeutic option for cutaneous melanoma in the last 30 years

The pembrolizumab, nivolumab and ipilimumab have been approved by the FDA for melanoma treatment. The first FDA-approved immune checkpoint inhibitor in metastatic melanoma is ipilimumab, a human monoclonal IgG1 antibody against CTLA-4

High dosages of IL-2 and interferons are the most commonly utilized drugs in biological immunotherapy

The first class of immunomodulatory drugs to be used in the treatment of melanoma is cytokines. Indeed, the FDA has approved both IL- 2 and IFN- $\alpha$ as adjuvant treatments for melanoma 


\section{INTRODUCTION}

Cancer is the world's second greatest cause of death, and it is a major public health concern. In 2021, 608,570 cancer deaths and 1,898,160 new cancer cases are predicted in the US $[1,2]$. Cutaneous melanoma is a more severe form of the disease that develops when melanocytes change and become malignant. Melanoma is the most serious skin cancer. It is less prevalent than basal cell and squamous cell carcinomas [3]. In recent decades, the cutaneous melanoma incidence has risen dramatically. Melanoma is the ninth most common type of cancer and the second leading cause of death. Every year, > 100,000 new instances of melanoma are detected in the US, with around 9000 deaths occurring from the disease [4]. When melanoma is detected early, surgical excision of the tumor is linked to a better prognosis. On the other hand, surgery is no longer sufficient for people who have advanced or metastatic disease locally. Localized melanoma has a 99\% 5-year survival rate, but distant metastases have a $20 \% 5$-year survival rate [5].

- Melanoma is one of the most susceptible cancers to immune suppression. High tumor mutational burden due to production of cancer-testis antigens, ultraviolet (UV) light exposure and pathogen-associated antigens mimicking melanocyte lineage proteins are all possible explanations for the sensitivity of melanoma cells to immune system activation $[6,7]$. In this case, the $T$ cell response appears to be crucial in preventing melanoma. The tumor infiltrated lymphocytes (TILs) play a crucial role in the anti-tumor immune response formation, and a fraction of TILs in melanoma patients shows cytolytic activity against autologous tumors. They are also linked to a better chance of survival and a decreased risk of metastasis [8]. Immunotherapy, molecularly targeted therapy and cytotoxic chemotherapy are current systemic treatment options for individuals with metastatic melanoma. The therapeutic landscape for melanoma patients has evolved dramatically since 2011, with the approval of 11 new medicines and combination regimens. Immunotherapy drugs, in particular, have been linked to long-term survival in responding individuals and have become the standard of care in most melanoma patients [9]. Melanoma has high immunogenicity due to its high immunogenicity; therefore, immunotherapy is one of the most effective therapeutic options. The mechanisms of action of immunotherapy are targeted at specific targets in the immune response's counter-regulatory processes [10]. Several therapeutic trials aimed at generating a T-cell response with local or systemic immunomodulatory medications have been conducted in recent decades, such as interleukin (IL)-2 [11], interferon (IFN)- $\alpha$ [12], cancer vaccines [13] and adoptive cell transfer [14]. In this review, we discussed recent developments in the field of immune-mediated therapy of melanoma. This article is based on previously conducted studies and does not contain any new studies with human participants or animals performed by any of the authors.

\section{EPIDEMIOLOGY}

Melanoma occurs in a moderately significant number of patients, with a global incidence rate of about 3 per 100,000 [15]. Globally, 352,000 new cases of melanoma were estimated to be diagnosed in 2015, with a 5 case per 100,000 age-standardized incidence rate. Melanoma led to the deaths of $>60,000$ people worldwide [16]. Males have a higher incidence rate than females, and it is linked to a lower median age at diagnosis ( 57 years) than other solid tumors (65 years) [15, 17]. Australasia (54\%), North America (21\%) and Western Europe (16\%) were found to have the highest incidence of melanoma [16]. Furthermore, the fact that global melanoma incidence rates are continuing to rise is highly alarming. There were about 225,000 new cases of melanoma in 2005 , but by 2015 , that number had risen to nearly 352,000 , a $56 \%$ increase [18]. While incidence rates of melanoma in Australia and North America are beginning to settle down, in Eastern and 
Southern Europe, they are still increasing [19]. As a result, melanoma is a significant cause of death and disease worldwide, necessitating new therapies and prevention strategies.

\section{PATHOPHYSIOLOGY AND CLINICAL SUBTYPES}

Melanoma's exact etiology is unknown [20]. However, the molecular and histological characteristics of the many melanoma subtypes have been extensively studied [21, 22]. Melanomas that develop from chronically sundamaged skin (CSD) have been found to occur in anatomical sites such as the neck and head. Non-CSD melanomas, on the other hand, are located in anatomical regions with little sun exposure, including the extremities and trunk [20]. In general, non-CSD melanomas have less mutation than CSD melanomas [20, 22]. Melanomas are closely attributed to benign melanocyte neoplasms. Naevi (commonly known as moles) are these lesions, and elevated levels of naevi are thought to be a melanoma risk factor $[20,23]$. Non-invasive melanoma, benign naevi and abnormal cellular characteristics in dysplastic naevi in situ are among these lesions $[20,24]$. Melanoma in situ is a type of melanoma limited to the epidermis and has a $100 \%$ survival rate if wholly removed [24]. The American Joint Committee on Cancer's (AJCC) current melanoma staging system is based on an examination of the tumor $(\mathrm{T})$, the presence of distant metastases (M) and the number of metastatic nodes $(\mathrm{N})[25,26]$. The clinical stages of cancer are subsequently grouped, ranging from 0 to stage IV [25]. Because distant metastases are present, stage IV melanoma is characterized as metastatic melanoma, whereas metastases exclusively distinguish stage III melanoma in regional lymph nodes (LN) [27].

Malignant melanoma has traditionally been divided into four histopathological subtypes, but certain melanomas cannot be categorized totally into either group [28]. Furthermore, this classification is based on morphological and clinical factors; it has minimal predictive significance, although it helps identify the disease's many histological presentations [28]. The four main melanoma subtypes are as follows: nodular melanoma (NM), lentigo maligna melanoma (LMM), superficial spreading melanoma (SSM) and acral lentiginous melanoma (ALM) [29]. However, several new clinical subgroups have been identified in recent years. Melanoma from a blue naevus, desmoplastic melanoma (DM) and persistent melanoma are examples of these [28].

\section{RISK FACTORS AND DRIVER MUTATIONS}

Melanoma develops as a result of a complicated interaction between environmental and genetic risk factors. UV rays from tanning beds and UV solar radiations are the critical environmental risk factors to be concerned about [30, 31]. Individual risk factors include a family history of melanoma, elevated levels of melanocytic naevi and skin complexion [31, 32]. Melanomas have one of the highest mutation rates of all solid malignancies [33]. As a result, current research is focusing on the molecular profiles linked with specific subtypes of melanoma. It is crucial to distinguish between "driving" mutations, which offer a survival advantage, and mutations that have little or no influence on tumor growth are known as "passenger" mutations [34]. The ability to create targeted therapies based on cancer's mutational landscapes allows for significant improvements in clinical outcomes. In 2015, researchers from The Cancer Genome Atlas Network published an extensive study revealing that the first complete genetic classification system for cutaneous melanomas was developed [35]. The significantly mutated genes' patterns, namely triple wild-type (WT), neurofibromin 1 (NF1), RAS and BRAF, which is related to greater copy numbers and structural rearrangement abnormalities but lacks mutations in the three genes mentioned above, were used to create these four distinct subtypes. These subtypes do not predict the outcome, but they may aid in identifying the genetic abnormalities linked to melanoma, hence identifying possible molecular targets [35]. It was also surprising to learn that immune cellular infiltrates and immune gene expression were associated 
with patient survival [35]. Although studies of the significant genetic anomalies in melanoma have been well covered elsewhere, this section will focus on a few of the most common driver mutations seen in cutaneous melanoma $[20,33,36]$.

\section{IMMUNOTHERAPY FOR CUTANEOUS MELANOMA}

Tumor immunotherapy is the use of pharmacological medicines to induce or replace host anti-tumor immunity in cancer patients. Immunotherapy's cytotoxic chemotherapy and resistance to radiation are one of its most distinguishing features. Dacarbazine was previously the most effective treatment for melanoma, with an overall response rate (ORR) of 10-20\%; however, there were no differences between dacarbazine monotherapy and combination treatment. For radiotherapy, no improved results have been documented. Despite the dismal clinical results, these approaches have been the main drivers in melanoma treatment for decades [37, 38]. Most immunotherapeutic drugs' mechanisms of action are unknown, but these treatments are significant for their capacity to provide a longterm benefit in a subset of patients [39]. In the metastatic situation, ipilimumab has been linked to a considerable increase in overall survival [40]. Several caveats must be considered while using immunotherapy. Even though therapy advantages might last for years, only a tiny percentage of patients respond.

Furthermore, immunotherapy's distinctive side effects, which are related to the induction of autoimmunity and pro-inflammatory-like states, may limit eligibility or provide clinical management issues [41]. In this case, the T-cell response appears to be crucial in preventing melanoma. Establishing an anti-tumor immune response requires TILs, and a fraction of TILs in melanoma patients show cytolytic activity against autologous tumors [8]. The various steps involved in the immunity cycle of cancer were represented in Fig. 1. Recently, the treatment of both metastatic and unresectable melanoma have dramatically changed by the programmed death-1 (PD-1) and immune checkpoint inhibitors (ICIs) against cytotoxic $\mathrm{T}$ lymphocyte antigen-4 (CTLA-4) as well as those at high risk for recurrence following resection (Table 1) $[42,43]$. Unfortunately, ICI therapy is beset by issues such as the lack of predictive response indicators and primary and secondary resistance [44]. Combining immunotherapy approaches helps to enhance response and decrease resistance, while biomarker identification is crucial for better patient selection.

\section{IMMUNE CHECKPOINT BLOCKADE (ICB)}

Drugs that target the inhibitory receptors CTLA4 and PD-1 to mediate ICB have been demonstrated to produce long-term responses in subsets of patients with cancers such as melanoma and renal cell cancer (RCC) $[52,53]$. Antibodies targeting the PD-1 ligand, PD-L1, are also tested in clinical studies and have objective responses in various cancer types $[54,55]$. To date, the Food and Drug Administration (FDA) has approved four mAbs for ICB therapy: (1) atezolizumab ( $\alpha$ PD-L1), (2) pembrolizumab ( $\alpha$ PD1); (3) nivolumab ( $\alpha \mathrm{PD}-1)$; (4) ipilimumab ( $\alpha$ CTLA-4) [56]. They have been approved treating a wide range of advanced and metastatic malignancies, including melanoma, which can range from resectable to metastatic and urothelial carcinoma (atezolizumab) $[56,57]$. Pembrolizumab, nivolumab and ipilimumab have been approved by the FDA for melanoma treatment [58]. Because checkpoint receptors are critical in regulating autoimmunity, the most serious side effects linked with ICB medications including immune-related adverse events (IRAEs) are a group of autoimmune symptoms [59]. IRAEs are prevalent, with rates ranging from $90 \%$ in those receiving CTLA-4 antibodies to 70\% in patients receiving PD-1/PD-L1 antibodies, and immunosuppressive medications must be used with caution in the clinic [59]. Biomarkers that can predict the efficacy of a specific ICB treatment are needed because ICB elicits objective responses in only a fraction of patients, or it is crucial to identify a 


\section{Cancer Cell Death and Antigen Release}

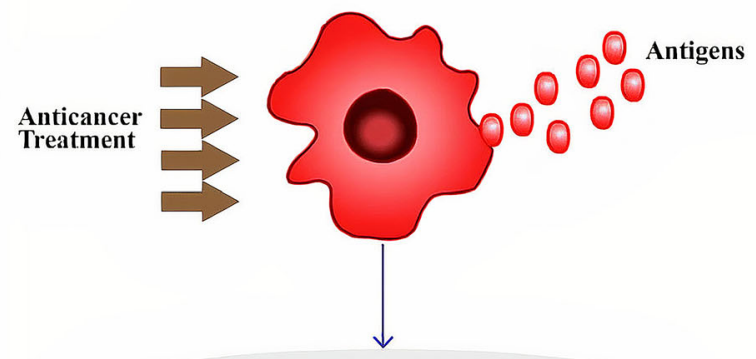

2. Cancer Antigen Presentation

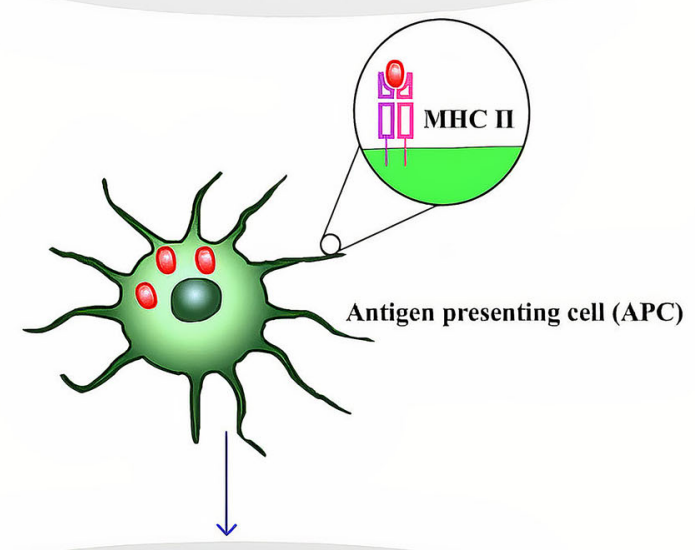

3. Priming and activation
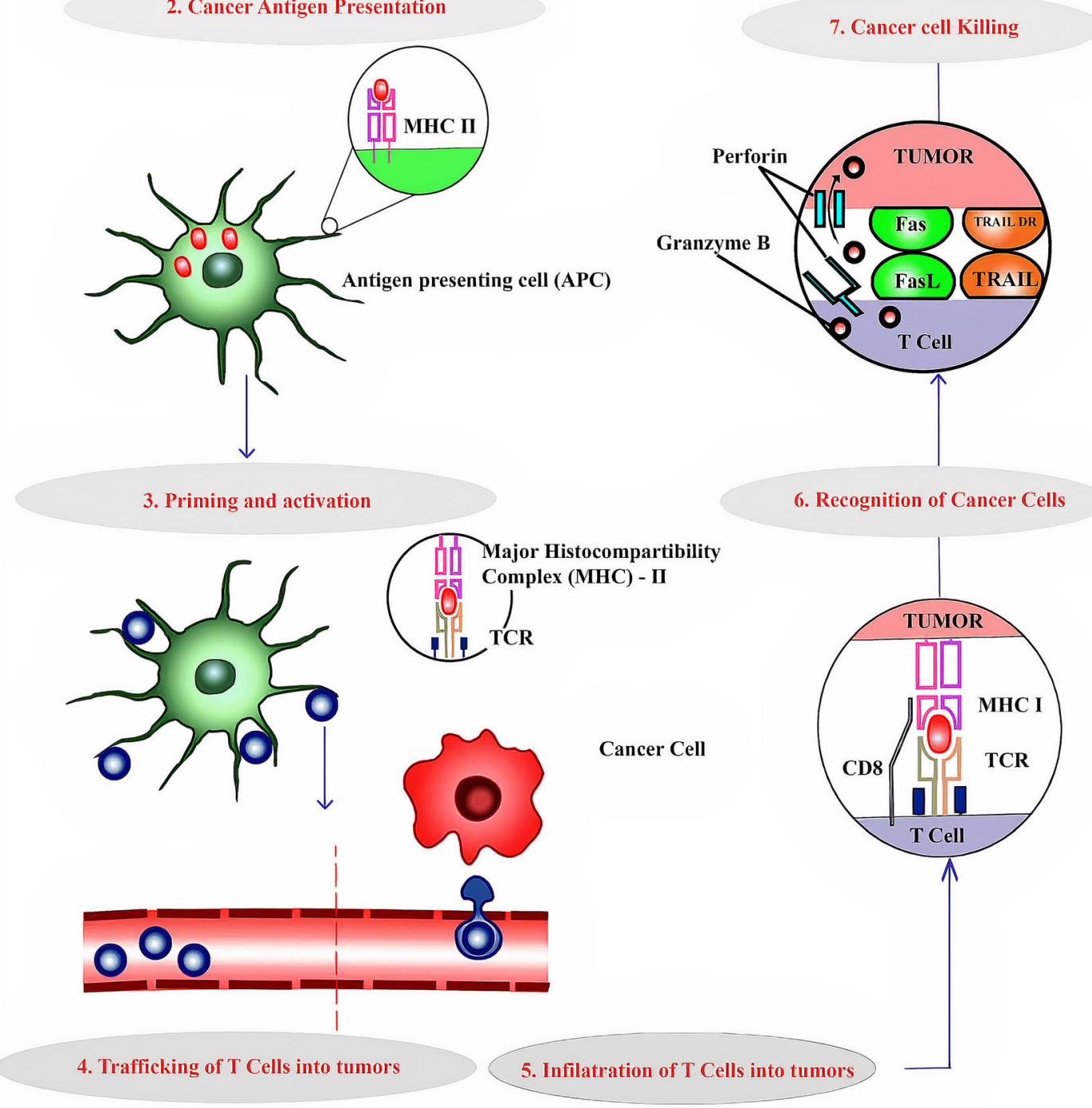

Fig. 1 Steps involved in the immunity cycle of cancer 
subset of patients who could benefit from ICB therapy [60].

\section{CTLA-4 BLOCKADE}

After CD28 binding and activation, CTLA-4, a member of the CD28 superfamily, is activated. CTLA-4's specific ligands are B7-1 and B7-2.
When CTLA-4 interacts with activated T cells, a downregulator signal is produced, which inhibits transcription of IL-2 and hence cell cycle progression [61, 62]. Ipilimumab is the most critical drug that inhibits CTLA-4 [47]; studies have indicated that this molecule has promising results and that the response is long-lasting, even after the treatment is stopped [63]. The first FDA-approved immune checkpoint

Table 1 Immunotherapy clinical trials in locally advanced and metastatic melanoma

\begin{tabular}{|c|c|c|c|c|c|c|}
\hline Trial name & Primary outcome & Treatment arms & $\begin{array}{l}\text { Median } \\
\text { OS } \\
\text { (months) }\end{array}$ & $\begin{array}{l}\text { Median } \\
\text { PFS } \\
\text { (months) }\end{array}$ & ORR (\%) & $\begin{array}{l}1 \text { year- } \\
\text { RFS } \\
(\%)\end{array}$ \\
\hline \multirow{3}{*}{$\begin{array}{l}\text { KEYNOTE-006 } \\
{[45,46]}\end{array}$} & \multirow[t]{3}{*}{ PFS, OS } & Pembrolizumab q3w & & 4.1 & 32.9 & - \\
\hline & & Pembrolizumab $\mathrm{q} 2 \mathrm{w}$ & $32.7 \mathrm{a}$ & 5.6 & 33.7 & - \\
\hline & & Ipilimumab & 16 & 3.4 & 11.9 & - \\
\hline \multirow{2}{*}{$\begin{array}{l}\text { CheckMate } 238 \\
\text { [47] }\end{array}$} & \multirow[t]{2}{*}{ RFS } & Ipilimumab & - & - & - & 60.8 \\
\hline & & Nivolumab & - & - & - & 70.5 \\
\hline \multirow[t]{2}{*}{ CA184-024 } & \multirow[t]{2}{*}{ OS } & Dacarbazine + ipilimumab & 11.2 & 3 & 15.2 & - \\
\hline & & Dacarbazine & 9.1 & 3 & 10.3 & - \\
\hline \multirow{2}{*}{$\begin{array}{l}\text { EORTC1325/ } \\
\text { KEYNOTE-054 } \\
{[48]}\end{array}$} & \multirow[t]{2}{*}{ RFS } & Placebo & - & - & - & 61 \\
\hline & & Pembrolizumab & - & - & - & 75.4 \\
\hline \multirow{3}{*}{$\begin{array}{l}\text { CheckMate } 067 \\
\text { [49] }\end{array}$} & \multirow[t]{3}{*}{ PFS, OS } & Nivolumab + ipilimumab & NR & 11.5 & 58 & - \\
\hline & & Nivolumab & 36.9 & 6.9 & 45 & - \\
\hline & & Ipilimumab & 19.9 & 2.9 & 19 & - \\
\hline \multirow{2}{*}{$\begin{array}{l}\text { CheckMate } 066 \\
\text { [50] }\end{array}$} & \multirow[t]{2}{*}{ OS } & Dacarbazine & 11.2 & 2.2 & 14.4 & - \\
\hline & & Nivolumab & 37.5 & 5.1 & 42.9 & - \\
\hline \multirow[t]{2}{*}{ OPTiM [51] } & \multirow{2}{*}{$\begin{array}{l}\text { Durable response } \\
\text { lasting } \geq 6 \\
\text { months }\end{array}$} & T-VEC & 23.3 & $\begin{array}{l}\text { Not } \\
\text { reported }\end{array}$ & $\begin{array}{l}\text { Not } \\
\quad \text { reported }\end{array}$ & - \\
\hline & & GM-CSF & 18.9 & $\begin{array}{l}\text { Not } \\
\text { reported }\end{array}$ & $\begin{array}{l}\text { Not } \\
\quad \text { reported }\end{array}$ & - \\
\hline \multirow[t]{4}{*}{ CA184-002 [52] } & \multirow[t]{4}{*}{ OS } & Ipilimumab & 10.1 & 2.9 & 11 & - \\
\hline & & gp100 vaccine & 6.4 & 2.8 & 1.5 & - \\
\hline & & gp100 & 10 & 2.8 & 5.7 & - \\
\hline & & Vaccine + ipilimumab & & & & \\
\hline
\end{tabular}

$q 2 w$ every 2 weeks, $q 3 w$ every 3 weeks, $N R$ not reached, $R F S$ relapse-free survival, $P F S$ progression-free survival, $O S$ overall survival, $O R R$ overall response rate 
inhibitor in metastatic melanoma is ipilimumab, a human monoclonal IgG1 antibody against CTLA-4. It was given four times at a $3 \mathrm{mg} / \mathrm{kg}$ dose every 3 weeks [47].

\section{PD-1 BLOCKADE}

PD-1 is an inhibitory cell surface molecule that reduces effector function and is expressed by activated $\mathrm{T}$ and $\mathrm{B}$ cells and natural killer lymphocytes $[64,65]$. Studies have shown that PD-1 levels are higher in melanoma, implying a significant downregulation of activated $\mathrm{T}$ lymphocytes, which aids tumor cell survival $[66,67]$. The presence of interferon-gamma-secreting cells from the microenvironment raises PDL-1 expression in melanoma. Pembrolizumab and Nivolumab target the interaction between PD- 1 and its ligands PDL- 1 and PDL-2. In melanoma, many trials comparing pembrolizumab and nivolumab to ipilimumab have found significant clinical effectiveness [68, 69]. The importance of measuring circulating PD1 + regulatory $\mathrm{T}$ cells to predict treatment response to PD-1 blockers such as pembrolizumab and nivolumab was recently recognized by Gambichler and his co-workers. After starting treatment with PD-1 blocking antibodies, the researchers discovered that circulating PD-1 + Tregs rapidly fall, resulting in a lower probability of disease progression and metastatic illness [70].

\section{COMBINATORIAL CHECKPOINT BLOCKADE}

Despite the enormous effectiveness of ICB, only a tiny percentage of patients have long-term therapeutic responses [58, 71]. Immune checkpoint therapies' potency, on the other hand, has ushered in a new era of cancer treatment by allowing them to be combined with traditional cancer treatments like targeted molecular therapy, radiation and chemotherapy (e.g., BRAF/ MEK inhibitors) [72, 73]. This section will primarily focus on the efficacy of combined checkpoint blockade therapy for melanoma. Despite this, no clinical data exist to distinguish between ICB and BRAFi/MEKi targeted therapy as first-line melanoma treatment, and a clinical trial (NCT02224781) is being done to compare clinical outcomes in patients who get checkpoint blockade drugs after targeted therapies vs. individuals who get targeted therapies after checkpoint blockade drugs [72].

\section{TALIMOGENE LAHERPAREPVEC (T- VEC)}

T-VEC is a genetically modified herpes simplex type 1 virus that selectively replicates in tumor cells, expresses granulocyte-macrophage colony-stimulating factor (GM-CSF) and increases MHC class I antigen loading to promote tumor antigen presentation by dendritic cells (DCs) [74]. In 2015, the FDA approved T-VEC for advanced melanoma. T-VEC was found to improve the response rate in unresected stage IIIB-IV melanoma patients in a phase 3 trial compared to GM-CSF (26 vs. 6\%). Most of the reactions occurred only at the injection site and nearby non-injected lesions (primarily lung and visceral sites), while few reactions were recorded in distant non-injected lesions [75]. T-VEC and ICIs in combination have yielded promising outcomes. The ORR was improved in the phase II study of T-VEC + ipilimumab vs. ipilimumab alone in individuals with advanced melanoma (39 vs. $18 \%$, respectively) [76]. In a phase Ib trial combining T-VEC with pembrolizumab, the verified objective response rate was $62 \%$, with a complete response rate of $33 \%$ immune-related response criteria [77]. MASTER KEY-265/KEYNOTE-034, a phase III trial (NCT02263508) comparing T-VEC with pembrolizumab to pembrolizumab alone, is expected to publish its findings soon.

\section{OTHER IMMUNOTHERAPY STRATEGIES}

\section{Biological Immunotherapy}

The biological immunotherapy was the first used in the treatment of metastatic melanoma to replace or complete the action of 
chemotherapy. High dosages of IL-2 and interferons are the most commonly utilized drugs in biological immunotherapy [78, 79]. Biological immunotherapy and stereotactic radiation are frequently combined [80, 81], although such combination techniques have yet to be validated, and except in clinical studies, only single-agent use is permitted; such combined techniques have yet to be proven.

\section{Cytokines}

The first class of immunomodulatory drugs to be used in the treatment of melanoma is cytokines. Indeed, the FDA has approved both IL-2 and IFN- $\alpha$ as adjuvant treatments for melanoma $[82,83]$. In preclinical and clinical settings, cytokines such as GM-CSF and IL-12, 15, 18 and 21 have shown promising outcomes. Because of their pleiotropic action and high toxicity, especially at high doses, a single-agent cytokine method does not appear to be practicable [82]. In light of this, NTRK-214 is a human recombinant IL-2 conjugated prodrug with the same amino acid sequence. The core of IL-2 is attached to six releasable polyethylene glycol (PEG) chains in vivo, which progressively release in the presence of oxygen, resulting in active IL- 2 conjugates [84]. The tolerance and efficacy of ipilimumab with nivolumab and NTRK-214 with nivolumab are analyzed in a phase I/II clinical trial (NCT02983045).

\section{Adoptive Cell Therapy}

To promote anticancer immunity, ex vivo modified cells are supplied directly to patients is known as adoptive cell therapy (ACT) $[85,86]$. To date, most ACT clinical trials have used autologous TIL collected and grown from excised melanoma tissue $[87,88]$. Other cell types, such as natural killer cells, have been explored for use in adoptive transfer therapy since the 1980s, but not as extensively as T cells [89]. As a result, the primary focus of this section will be on $\mathrm{T}$ cell ACT research. This approach has the advantage of allowing tumorspecific cells to develop ex vivo without being impacted by the immunosuppressive tumor microenvironment (TME), and they may be given in large enough doses to cause tumor regression [86]. As previously indicated, Rosenberg and colleagues pioneered this field by utilizing autologous TIL from metastatic melanoma patients, which generated long-term anticancer responses [90]. Since then, advances in molecular biology have enabled the identification of a variety of tumor antigens as well as the production of genetically altered $\mathrm{T}$ cell products with chimeric antigen receptors (CARs) or tumor-specific $\mathrm{T}$ cell receptor (TCR) $[86,91]$.

\section{IDO Inhibitors}

Indoleamine 2,3-dioxygenase 1 (IDO1) is an enzyme involved in tryptophan degradation that has a significant immunosuppressive effect within the TME. Several IDO inhibitors (BMS986205, indiximod and epacadostat) are now being studied in combination with pembrolizumab, nivolumab or ipilimumab clinical trials [5]. Unfortunately, in phase III clinical trial ECHO-301/KEYNOTE-252, which compared epcadostat to pembrolizumab alone with pembrolizumab in advanced melanoma, the pembrolizumab with epcadostat group failed to show a PFS benefit [92].

\section{Cancer Vaccines}

Infectious disease vaccination is a pivotal point in human medicine. Cancer vaccines aim to activate the immune system, particularly the $\mathrm{T}$ cells, to attack the tumor by combining the tumor antigen with an adjuvant [93]. The vaccines might be a single-target antigen or polyvalent, with autologous tumor lysates or whole allogeneic cells [94]. To date, no vaccination combination has exhibited the same effectiveness in established malignancies as checkpoint blockade or ACT $[93,95]$. Metastatic melanoma patients who received IL-2 and a gp100 peptide vaccine fared better than those who received only IL-2, according to research by Schwartzentruber et al. published in 2011 $[94,96]$. However, cancer vaccination for solid tumors is particularly problematic because of 
Table 2 Key immunotherapeutics and their primary mechanisms of action

\begin{tabular}{|c|c|c|c|}
\hline Treatment & Mechanism(s) of action & Clinically tested agents & References \\
\hline \multicolumn{4}{|l|}{ Cytokines } \\
\hline $\begin{array}{l}\text { Interferon } \\
\text { alpha }\end{array}$ & $\begin{array}{l}\text { Activate multiple facets of immunity and has direct } \\
\text { effects on tumor cells }\end{array}$ & $\begin{array}{l}\text { Interferon alfa } 2 \mathrm{~b} \text { (Intron } \mathrm{A}, \\
\text { Sylatron }^{\mathrm{TM}} \text { ) }\end{array}$ & {$[97,98]$} \\
\hline Interleukin-2 & Activates and expands $\mathrm{T}$ cell & Aldeslesukin (proleukin) & {$[99,100]$} \\
\hline \multicolumn{4}{|l|}{ Vaccines } \\
\hline $\begin{array}{l}\text { Oncolytic viral } \\
\text { vaccines }\end{array}$ & $\begin{array}{l}\text { Viral induction of tumor cell lysis and adjuvant medical } \\
\text { host immune activation }\end{array}$ & $\begin{array}{l}\text { Talimogene laherparepvec }(\mathrm{T}- \\
\left.\text { VEC/Imlygic }^{\mathrm{TM}}\right)\end{array}$ & {$[51,101]$} \\
\hline $\begin{array}{l}\text { Peptide } \\
\text { vaccines }\end{array}$ & Induction of tumor-specific adaptive immunity & $\begin{array}{l}\text { Various tumor antigen peptides/ } \\
\text { lysates }+ \text { adjuvant })\end{array}$ & {$[93,95]$} \\
\hline $\begin{array}{l}\text { Cell-based } \\
\text { vaccines }\end{array}$ & Induction of tumor-specific adaptive immunity & $\begin{array}{l}\text { Tumor cells or activated DC/ } \\
\text { APC }\end{array}$ & {$[102,103]$} \\
\hline \multicolumn{4}{|c|}{ Adoptive $\mathrm{T}$ cell therapy } \\
\hline $\begin{array}{l}\text { Engineered T } \\
\text { cells }\end{array}$ & $\begin{array}{l}\text { Infusion of engineered } \mathrm{T} \text { cells specific for tumor } \\
\text { antigens }\end{array}$ & $\begin{array}{l}\text { Transgenic TCR or CAR bearing } \\
\mathrm{T} \text { lymphocytes }\end{array}$ & {$[86,87]$} \\
\hline TIL & Infusion of pool anti-tumor $\mathrm{T}$ cells & Ex vivo expanded TIL & {$[85,86]$} \\
\hline \multicolumn{4}{|c|}{ Immune activating mAbs } \\
\hline$\alpha \mathrm{LAG}-3$ & Blockade of T cell surface inhibitory molecule & BMS986016 & {$[58]$} \\
\hline$\alpha \mathrm{KIR}$ & Blockade of NK cell inhibitory receptor & Lirilumab & {$[104,105]$} \\
\hline $\begin{array}{l}\alpha \mathrm{CD} 137(4- \\
1 \mathrm{BB})\end{array}$ & Against of $\mathrm{T}$ cell costimulatory receptor & Urelumab & {$[106]$} \\
\hline$\alpha \mathrm{PD}-\mathrm{L} 1$ & $\begin{array}{l}\text { Blockade of inhibitory checkpoint ligand expressed on } \\
\text { immune cells and tumor cells }\end{array}$ & $\begin{array}{l}\text { Atezolizumab, durvalumab, } \\
\text { avelumab }\end{array}$ & {$[58,66]$} \\
\hline$\alpha P D-1$ & Blockade of inhibitory checkpoint receptor & $\begin{array}{l}\text { Nivolumab (Opdivo), } \\
\text { pembrolozumab (Keytruda), }\end{array}$ & {$[57,58]$} \\
\hline$\alpha C T L A-4$ & $\begin{array}{l}\text { Blockade of } \mathrm{T} \text { cell checkpoint receptor } \\
\text { Depletion of intratumoral Treg }\end{array}$ & Ipilimumab (Yervoy) & {$[58,71]$} \\
\hline
\end{tabular}

the immunosuppressive TME and a constantly expanding tumor-targeted immune escape [95]. Several key immunotherapeutics and their primary mechanisms of action are presented in Table 2.

\section{Immunotherapy Biomarkers}

The success of targeted therapy is based on the presence of a specific tumor feature, such as the
BRAF V600 mutation, that drives tumor growth and serves as a specific biomarker of response to treatment that targets the aberrant pathway. Primary and secondary resistance to targeted therapy in melanoma is challenging to solve, and various researchers have attempted to improve BRAF V600 detection of prognostic and predictive indicators [107, 108]. Despite extensive attempts, biomarker response to melanoma immunotherapy, notably ICIs, approved for 
clinical use, is lacking. This is especially crucial because of the relatively low response rate of immunotherapy. In clinical trials, including inhibitors of the PD-1/PD-L1 axis, immunohistochemistry (IHC) labeling of PD-L1 expression has been employed as a biomarker. The role of PD-L1 in patient stratification has yielded conflicting results across trials using PD-L1 IHC antibodies with non-homogeneous cut-off values $[68,109]$. Although PD-L1 is not currently considered a good stratification marker, it needs additional investigation because it could reveal biological insights [72]. To better characterize the TME and establish predictive immunotherapy biomarkers, more comprehensive models are being investigated.

In this respect, Tumeh et al. [72] observed that near the invasive tumor margin, CD8 $+\mathrm{T}$ lymphocytes are present that trigger elevation of expression of PD-L1 on melanoma cells, which may better explain responsiveness to anti-PD-1 mAbs or primary resistance. As a response marker, a gene-expression profile has been proposed [110]. The primary mediator of anti-tumor inflammation is IFN $\gamma$, which is secreted by CD8+ T cells. A gene expression profile known as 'T-cell-inflamed tumor' has been linked to responsiveness to various immunotherapies, including cancer vaccines, ICIs and IL-2 [111, 112]. Moreover, primary and secondary resistance to PD-1/PD-L1 pathway inhibitors is associated with a low IFN $\gamma$ gene expression signature that can be mediated by activation of PTEN and $\mathrm{WNT} / \beta$-catenin pathway, impairment of JAK2 signaling or alteration of antigen presentation through structural or functional impairment of MHC class I mediated antigen presentation [113, 114]. The most considerable complete exome and transcriptome sequencing research of tumor samples from metastatic melanoma patients using ICI has been published [115]. The findings back up the correlations between treatment response and baseline immune infiltrate. However, they also show that tumor mutational burden has inconsistent associations and that transcriptomic features and multiple novels genomic, including features associated with MHC-I and MHC-II antigen presentation, can predict selective response. In addition, the researchers developed predictive models that included transcriptomic, genomic and clinical data to identify melanoma patients who were intrinsically resistant to anti-PD1 mAb [115]. A growing number of researchers seek to connect ICI efficacy to circulating tumor DNA PD-L1 expression levels [116, 117]. Several studies have suggested that measuring matrix metalloproteinases (MMPs), which are known to play a vital role in melanoma progression, could be a reliable predictor of immunotherapy response $[118,119]$. Adjuvant immunotherapy was used to treat primary melanoma tumors; Moogk et al. [120] discovered that the MMP-23 expression and anti-tumor T-cell response have an inverse association. According to the authors, MMP-23 expression is correlated with shorter PFS, so it could be a viable therapeutic target in melanoma and a biomarker for monitoring melanoma patients' immunotherapy response.

\section{CONCLUSION}

Over the last decade, significant advancements in melanoma treatment have been made. Immunotherapy is a well-established treatment option for melanoma patients, with some individuals experiencing long-term benefits. Researchers' tireless efforts have given information on key pathways in melanoma biology, paving the way for targeted treatment and immunotherapy. These drugs have distinct modes of action and toxicity profiles, necessitating careful patient selection and management. Tumor immunotherapy, when used correctly, can provide significant benefits to melanoma patients.

\section{ACKNOWLEDGEMENTS}

Funding. This article was self-funded, and no other source of funding present. The Rapid Service Fee was funded by the author.

Authorship. Named author meets the International Committee of Medical Journal Editors (ICMJE) criteria for authorship for this article, 
takes responsibility for the integrity of the work as a whole, and has given her approval for this version to be published.

Author Contribution. Dr. Piyu Parth Naik contributed to manuscript writing.

Disclosures. Dr. Piyu Parth Naik has nothing to disclose.

Compliance with Ethics Guidelines. This article is based on previously conducted studies and does not contain any new studies with human participants or animals performed by any of the authors.

Data Availability. Data sharing is not applicable to this article as no datasets were generated or analyzed during the current study.

Open Access. This article is licensed under a Creative Commons Attribution-NonCommercial 4.0 International License, which permits any non-commercial use, sharing, adaptation, distribution and reproduction in any medium or format, as long as you give appropriate credit to the original author(s) and the source, provide a link to the Creative Commons licence, and indicate if changes were made. The images or other third party material in this article are included in the article's Creative Commons licence, unless indicated otherwise in a credit line to the material. If material is not included in the article's Creative Commons licence and your intended use is not permitted by statutory regulation or exceeds the permitted use, you will need to obtain permission directly from the copyright holder. To view a copy of this licence, visit http://creativecommons.org/licenses/by$\mathrm{nc} / 4.0 /$.

\section{REFERENCES}

1. Ram-Kumar A, Rajagopal K, Meenambiga SS, Kumaresan S. In vitro and in silico anti-breast cancer analysis of bioactive metabolites of bacillus subtilis isolated from soil. Saudi J Pathol Microbiol. 2020;05(4):220-9. https://doi.org/10.36348/sjpm. 2020.v05i04.006.
2. Siegel RL, Miller KD, Fuchs HE, Jemal A. Cancer statistics, 2021. CA Cancer J Clin. 2021;71(1):7-33. https://doi.org/10.3322/caac.21654.

3. Foletto MC, Haas SE. Cutaneous melanoma: new advances in treatment. An Bras Dermatol. 2014;89(2): 301-10. https://doi.org/10.1590/abd1806-4841. 20142540.

4. Passarelli A, Mannavola F, Stucci LS, Tucci M, Silvestris $\mathrm{F}$. Immune system and melanoma biology: a balance between immunosurveillance and immune escape. Oncotarget 2017;8(62):106132 [Online]. https://www.ncbi.nlm.nih.gov/pmc/articles/ PMC5739707/.

5. Leonardi G, Candido S, Falzone L, Spandidos D, Libra M. Cutaneous melanoma and the immunotherapy revolution. Int J Oncol. 2020;57(3):609-18. https:// doi.org/10.3892/ijo.2020.5088 (Review).

6. Faramarzi S, Ghafouri-Fard S. Melanoma: a prototype of cancer-testis antigen-expressing malignancies. Immunotherapy 2017; 9(13):1103-13 [Online]. https://www.futuremedicine.com/doi/abs/10.2217/ imt-2017-0091.

7. Candido S et al. Analysis of the B-RafV600E mutation in cutaneous melanoma patients with occupational sun exposure. Oncol Rep 2014;31(3):1079-82 [Online]. https://www.spandidos-publications.com/or/ 31/3/1079.

8. Lee N, Zakka N, Mihm Jr MC, Schatton T. Tumourinfiltrating lymphocytes in melanoma prognosis and cancer immunotherapy. Pathology 2016;48(2): 177-87 [Online]. https://www.sciencedirect.com/ science/article/pii/S0031302515000331.

9. Sullivan RJ, et al. An update on the Society for Immunotherapy of Cancer consensus statement on tumor immunotherapy for the treatment of cutaneous melanoma: version 2.0. J Immunother Cancer. 2018;6(1):44. https://doi.org/10.1186/s40425018-0362-6.

10. Ralli M, et al. Immunotherapy in the treatment of metastatic melanoma: current knowledge and future directions. J Immunol Res. 2020;2020:1-12. https://doi.org/10.1155/2020/9235638.

11. Rosenberg SA. IL-2: the first effective immunotherapy for human cancer. J Immunol 2014;192(12):5451-8 [Online]. https://www.jimmunol.org/content/192/ 12/5451.short.

12. Wheatley K, Ives N, Hancock B, Gore M, Eggermont A, Suciu S. Does adjuvant interferon- for high-risk melanoma provide a worthwhile benefit? A meta-analysis of the randomised trials. Cancer Treat Rev 2003;29(4): 241-52 [Online]. https://www.sciencedirect.com/ science/article/pii/S0305737203000744. 
13. Schwartzentruber DJ, et al. gp100 peptide vaccine and interleukin-2 in patients with advanced melanoma. N Engl J Med. 2011;364(22):2119-27.

14. Rohaan MW, van den Berg JH, Kvistborg P, Haanen JBAG. Adoptive transfer of tumor-infiltrating lymphocytes in melanoma: a viable treatment option. $\mathrm{J}$ Immunother Cancer 2018;6(1):1-16 [Online]. https://jitc.biomedcentral.com/articles/10.1186/ s40425-018-0391-1.

15. Siegel R, Miller K, Jemal A. Cancer statistics, 2017. CA Cancer J Clin. 2017;67(1):7-30. https://doi.org/ 10.3322/caac. 21387.

16. Karimkhani $\mathrm{C}$, et al. The global burden of melanoma: results from the Global Burden of Disease Study 2015. Br J Dermatol. 2017;177(1):134-40. https://doi.org/10.1111/bjd.15510.

17. Ali Z, Yousaf N, Larkin J. Melanoma epidemiology, biology and prognosis. Eur J Cancer Suppl. 2013;11(2):81-91. https://doi.org/10.1016/j.ejcsup. 2013.07.012.

18. Fitzmaurice $\mathrm{C}$, et al. Global, regional, and national cancer incidence, mortality, years of life lost, years lived with disability, and disability-adjusted life-years for 32 cancer groups, 1990-2015. JAMA Oncol. 2017;3(4): 524. https://doi.org/10.1001/jamaoncol.2016.5688.

19. Erdmann $\mathrm{F}$, et al. International trends in the incidence of malignant melanoma 1953-2008-are recent generations at higher or lower risk? Int J Cancer. 2013;132(2):385-400. https://doi.org/10. 1002/ijc.27616.

20. Shain AH, Bastian BC. From melanocytes to melanomas. Nat Rev Cancer. 2016;16(6):345-58. https:// doi.org/10.1038/nrc.2016.37.

21. Bastian BC. The molecular pathology of melanoma: an integrated taxonomy of melanocytic neoplasia. Annu Rev Pathol Mech Dis. 2014;9(1):239-71. https://doi.org/10.1146/annurev-pathol-012513104658.

22. Viros A, et al. Improving melanoma classification by integrating genetic and morphologic features. PLoS Med. 2008;5(6): e120. https://doi.org/10.1371/ journal.pmed.0050120.

23. Bandarchi B, Jabbari CA, Vedadi A, Navab R. Molecular biology of normal melanocytes and melanoma cells. J Clin Pathol. 2013;66(8):644-8. https://doi.org/10.1136/jclinpath-2013-201471.

24. Hussein MR. Melanocytic dysplastic naevi occupy the middle ground between benign melanocytic naevi and cutaneous malignant melanomas: emerging clues. J Clin Pathol. 2005;58(5):453-6. https://doi.org/10.1136/jcp.2004.019422.
25. Balch CM, et al. Final version of 2009 AJCC melanoma staging and classification. J Clin Oncol. 2009;27(36): 6199-206. https://doi.org/10.1200/JCO.2009.23.4799.

26. Eggermont AM, Spatz A, Robert C. Cutaneous melanoma. Lancet. 2014;383(9919):816-27. https:// doi.org/10.1016/S0140-6736(13)60802-8.

27. Bichakjian $\mathrm{CK}$, et al. Guidelines of care for the management of primary cutaneous melanoma. J Am Acad Dermatol. 2011;65(5):1032-47. https:// doi.org/10.1016/j.jaad.2011.04.031.

28. Scolyer RA, Long GV, Thompson JF. Evolving concepts in melanoma classification and their relevance to multidisciplinary melanoma patient care. Mol Oncol. 2011;5(2):124-36. https://doi.org/10. 1016/j.molonc.2011.03.002.

29. Smoller BR. Histologic criteria for diagnosing primary cutaneous malignant melanoma. Mod Pathol. 2006;19(S2):S34-40. https://doi.org/10. 1038/modpathol.3800508.

30. Le Clair MZ, Cockburn MG. Tanning bed use and melanoma: establishing risk and improving prevention interventions. Prev Med Reports. 2016;3: 139-44. https://doi.org/10.1016/j.pmedr.2015.11. 016.

31. Rastrelli M, Tropea S, Rossi CR, Alaibac M. Melanoma: epidemiology, risk factors, pathogenesis, diagnosis and classification. In Vivo (Brooklyn) 2014;28(6): 1005-11 [Online]. https://iv.iiarjournals.org/content/ 28/6/1005.short.

32. Liu Y, Sheikh MS. Melanoma: molecular pathogenesis and therapeutic management. Mol Cell Pharmacol 2014;6(3):228 [Online]. https://www.ncbi. nlm.nih.gov/pmc/articles/PMC4346328/.

33. Reddy BY, Miller DM, Tsao H. Somatic driver mutations in melanoma. Cancer. 2017;123(S11): 2104-17. https://doi.org/10.1002/cncr.30593.

34. Stratton MR, Campbell PJ, Futreal PA. The cancer genome. Nature. 2009;458(7239):719-24. https:// doi.org/10.1038/nature07943.

35. Akbani R, et al. Genomic classification of cutaneous melanoma. Cell. 2015;161(7):1681-96. https://doi. org/10.1016/j.cell.2015.05.044.

36. Hawryluk EB, Tsao H. Melanoma: clinical features and genomic insights. Cold Spring Harb Perspect Med. 2014;4(9):a015388-a015388. https://doi.org/ $10.1101 /$ cshperspect.a015388.

37. Franken MG, Leeneman B, Gheorghe M, Uyl-de Groot CA, Haanen JBAG, van Baal PHM. A systematic literature review and network meta-analysis of effectiveness and safety outcomes in advanced 
melanoma. Eur J Cancer 2019;123:58-71 [Online]. https://www.sciencedirect.com/science/article/pii/ S0959804919307257.

38. Tran KB, Buchanan CM, Shepherd PR. Evolution of molecular targets in melanoma treatment. Curr Pharm Des 2020;26(4):396-414 [Online]. https:// www.ingentaconnect.com/content/ben/cpd/2020/ 00000026/00000004/art00002.

39. Prieto PA et al. CTLA-4 blockade with ipilimumab: long-term follow-up of 177 patients with metastatic melanoma. Clin Cancer Res 2012;18(7):2039-47 [Online]. https://clincancerres.aacrjournals.org/ content/18/7/2039.short.

40. Robert $\mathrm{C}$ et al. Ipilimumab plus dacarbazine for previously untreated metastatic melanoma. N Engl J Med 2011;364(26):2517-26 [Online]. https://www. nejm.org/doi/full/10.1056/Nejmoa1104621.

41. Kaufman HL et al. The Society for Immunotherapy of Cancer consensus statement on tumour immunotherapy for the treatment of cutaneous melanoma. Nat Rev Clin Oncol 2013;10(10):588-98 [Online]. https://www.nature.com/articles/nrclinonc. 2013.153.

42. Weber JS, et al. Nivolumab versus chemotherapy in patients with advanced melanoma who progressed after anti-CTLA-4 treatment (CheckMate 037): a randomised, controlled, open-label, phase 3 trial. Lancet Oncol. 2015;16(4):375-84. https://doi.org/ $10.1016 /$ S1470-2045(15)70076-8.

43. Ascierto PA, et al. Cobimetinib combined with vemurafenib in advanced BRAFV600-mutant melanoma (coBRIM): updated efficacy results from a randomised, double-blind, phase 3 trial. Lancet Oncol. 2016;17(9):1248-60. https://doi.org/10. 1016/S1470-2045(16)30122-X.

44. Christofi T, Baritaki S, Falzone L, Libra M, Zaravinos A. Current perspectives in cancer immunotherapy. Cancers (Basel). 2019;11(10):1472. https://doi.org/ 10.3390/cancers11101472.

45. Robert C, et al. Pembrolizumab versus ipilimumab in advanced melanoma (KEYNOTE-006): post-hoc 5-year results from an open-label, multicentre, randomised, controlled, phase 3 study. Lancet Oncol. 2019;20(9):1239-51. https://doi.org/10. 1016/S1470-2045(19)30388-2.

46. Schachter J, et al. Pembrolizumab versus ipilimumab for advanced melanoma: final overall survival results of a multicentre, randomised, openlabel phase 3 study (KEYNOTE-006). Lancet. 2017;390(10105):1853-62. https://doi.org/10.1016/ S0140-6736(17)31601-X.
47. Weber J, et al. Adjuvant nivolumab versus ipilimumab in resected stage III or IV melanoma. $\mathrm{N}$ Engl J Med. 2017;377(19):1824-35. https://doi.org/10. 1056/NEJMoa1709030.

48. Eggermont AMM, et al. Adjuvant pembrolizumab versus placebo in resected stage III melanoma. N Engl J Med. 2018;378(19):1789-801. https://doi. org/10.1056/NEJMoa1802357.

49. Larkin J, et al. Five-year survival with combined nivolumab and ipilimumab in advanced melanoma. N Engl J Med. 2019;381(16):1535-46. https://doi.org/10.1056/NEJMoa1910836.

50. Ascierto PA, et al. Survival outcomes in patients with previously untreated BRAF wild-type advanced melanoma treated with nivolumab therapy. JAMA Oncol. 2019;5(2):187. https://doi.org/10.1001/jamaoncol. 2018.4514 .

51. Andtbacka RHI, et al. Talimogene laherparepvec improves durable response rate in patients with advanced melanoma. J Clin Oncol. 2015;33(25): 2780-8. https://doi.org/10.1200/JCO.2014.58.3377.

52. Hodi FS, et al. Improved survival with ipilimumab in patients with metastatic melanoma. $\mathrm{N}$ Engl J Med. 2010;363(8):711-23. https://doi.org/10.1056/ NEJMoa1003466.

53. Robert C, et al. Nivolumab in previously untreated melanoma without BRAF mutation. N Engl J Med. 2015;372(4):320-30. https://doi.org/10.1056/NEJMoa 1412082.

54. Brahmer JR, et al. Safety and activity of anti-PD-L1 antibody in patients with advanced cancer. N Engl J Med. 2012;366(26):2455-65. https://doi.org/10. 1056/NEJMoa1200694.

55. Herbst RS, et al. Predictive correlates of response to the anti-PD-L1 antibody MPDL3280A in cancer patients. Nature. 2014;515(7528):563-7. https:// doi.org/10.1038/nature14011.

56. Pitt JM, et al. Resistance mechanisms to immunecheckpoint blockade in cancer: tumor-intrinsic and -extrinsic factors. Immunity. 2016;44(6):1255-69. https://doi.org/10.1016/j.immuni.2016.06.001.

57. Zou W, Wolchok JD, Chen L. PD-L1 (B7-H1) and PD-1 pathway blockade for cancer therapy: mechanisms, response biomarkers, and combinations. Sci Transl Med. 2016;8(328):328rv4. https://doi.org/10. 1126/scitranslmed.aad7118.

58. Baumeister SH, Freeman GJ, Dranoff G, Sharpe AH. Coinhibitory pathways in immunotherapy for cancer. Annu Rev Immunol. 2016;34(1):539-73. https://doi.org/10.1146/annurev-immunol-032414112049. 
59. Michot JM, et al. Immune-related adverse events with immune checkpoint blockade: a comprehensive review. Eur J Cancer. 2016;54:139-48. https:// doi.org/10.1016/j.ejca.2015.11.016.

60. Topalian SL, Taube JM, Anders RA, Pardoll DM. Mechanism-driven biomarkers to guide immune checkpoint blockade in cancer therapy. Nat Rev Cancer 2016;16(5):275-87 [Online]. https://www. nature.com/articles/nrc.2016.36.

61. Buchbinder EI, Desai A. CTLA-4 and PD-1 pathways. Am J Clin Oncol. 2016;39(1):98-106. https://doi. org/10.1097/COC.0000000000000239.

62. Lipson EJ, Drake CG. Ipilimumab: an anti-CTLA-4 antibody for metastatic melanoma. Clin Cancer Res. 2011;17(22):6958-62. https://doi.org/10.1158/ 1078-0432.CCR-11-1595.

63. Buchbinder EI, Hodi FS. Immune-checkpoint blockade-durable cancer control. Nat Rev Clin Oncol. 2016;13(2):77-8. https://doi.org/10.1038/ nrclinonc.2015.237.

64. Wilson MA, Schuchter LM. Chemotherapy for melanoma. Cham: Springer; 2016. p. 209-29.

65. Uhara H. Recent advances in therapeutic strategies for unresectable or metastatic melanoma and realworld data in Japan. Int J Clin Oncol. 2019;24(12): 1508-14. https://doi.org/10.1007/s10147-018-1246y.

66. Iwai Y, Hamanishi J, Chamoto K, Honjo T. Cancer immunotherapies targeting the PD-1 signaling pathway. J Biomed Sci. 2017;24(1):26. https://doi. org/10.1186/s12929-017-0329-9.

67. Sadozai H, Gruber T, Hunger RE, Schenk M. Recent successes and future directions in immunotherapy of cutaneous melanoma. Front Immunol. 2017. https://doi.org/10.3389/fimmu.2017.01617.

68. Robert C, et al. Pembrolizumab versus ipilimumab in advanced melanoma. N Engl J Med. 2015;372(26): 2521-32. https://doi.org/10.1056/NEJMoa1503093.

69. Postow MA, Callahan MK, Wolchok JD. Immune checkpoint blockade in cancer therapy. J Clin Oncol. 2015;33(17):1974-82. https://doi.org/10. 1200/JCO.2014.59.4358.

70. Gambichler T, Schröter U, Höxtermann S, Susok L, Stockfleth E, Becker JC. Decline of programmed death-1-positive circulating $\mathrm{T}$ regulatory cells predicts more favourable clinical outcome of patients with melanoma under immune checkpoint blockade. Br J Dermatol. 2020;182(5):1214-20. https:// doi.org/10.1111/bjd.18379.
71. Topalian SL, Drake CG, Pardoll DM. Immune checkpoint blockade: a common denominator approach to cancer therapy. Cancer Cell. 2015;27(4):450-61. https://doi.org/10.1016/j.ccell. 2015.03.001.

72. Luke JJ, Flaherty KT, Ribas A, Long GV. Targeted agents and immunotherapies: optimizing outcomes in melanoma. Nat Rev Clin Oncol. 2017;14(8): 463-82. https://doi.org/10.1038/nrclinonc.2017.43.

73. Sindoni A, Minutoli F, Ascenti G, Pergolizzi S. Combination of immune checkpoint inhibitors and radiotherapy: review of the literature. Crit Rev Oncol Hematol. 2017;113:63-70. https://doi.org/ 10.1016/j.critrevonc.2017.03.003.

74. Conry RM, Westbrook B, McKee S, Norwood TG. Talimogene laherparepvec: first in class oncolytic virotherapy. Hum Vaccine Immunother 2018;14(4): 839-46 [Online]. https://www.tandfonline.com/ doi/abs/10.1080/21645515.2017.1412896.

75. Andtbacka RH et al. Talimogene laherparepvec improves durable response rate in patients with advanced melanoma. J Clin Oncol 2015;33(25): 2780-88 [Online]. https://www.researchgate.net/ profile/Gregory_Daniels/publication/277412748_ Talimogene_Laherparepvec_Improves_Durable_ Response_Rate_in_Patients_With_Advanced_Melanoma/ links/556dc0d708aeab777225a86b/TalimogeneLaherparepvec-Improves-Durable-Response-Rate-in.

76. Chesney J et al. Randomized, open-label phase II study evaluating the efficacy and safety of talimogene laherparepvec in combination with ipilimumab versus ipilimumab alone in patients with advanced, unresectable melanoma. J Clin Oncol 2018;36(17):1658 [Online]. https://www.ncbi.nlm. nih.gov/pmc/articles/pmc6075852/.

77. Ribas A et al. Oncolytic virotherapy promotes intratumoral $\mathrm{T}$ cell infiltration and improves antiPD-1 immunotherapy. Cell 2017;170(6):1109-19 [Online]. https://www.sciencedirect.com/science/ article/pii/S0092867417309522.

78. Sanlorenzo M, et al. Role of interferon in melanoma: old hopes and new perspectives. Expert Opin Biol Ther. 2017;17(4):475-83. https://doi.org/10. 1080/14712598.2017.1289169.

79. Livingstone A, Agarwal A, Stockler MR, Menzies AM, Howard K, Morton RL. Preferences for immunotherapy in melanoma: a systematic review. Ann Surg Oncol. 2020;27(2):571-84. https://doi. org/10.1245/s10434-019-07963-y.

80. Seung SK, et al. Phase 1 study of stereotactic body radiotherapy and interleukin-2-tumor and immunological responses. Sci Transl Med. 
2012;4(137):137ra74. scitranslmed.3003649.

https://doi.org/10.1126/

81. Haanen JBAG. Immunotherapy of melanoma. Eur J Cancer Suppl. 2013;11(2):97-105. https://doi.org/ 10.1016/j.ejcsup.2013.07.013.

82. Nicholas C, Lesinski GB. Immunomodulatory cytokines as therapeutic agents for melanoma. Immunotherapy 2011;3(5):673-90 [Online]. https:// www.futuremedicine.com/doi/abs/10.2217/imt.11. 45 .

83. Kawakami Y, Rosenberg SA. T cell recognition of self peptides as tumor rejection antigens. Immunol Res 1996;15(3):179-90 [Online]. https://link.springer. com/content/pdf/10.1007/BF02918248.pdf.

84. Charych DH et al. NKTR-214, an engineered cytokine with biased IL2 receptor binding, increased tumor exposure, and marked efficacy in mouse tumor models. Clin Cancer Res 2016;22(3):680-90 [Online]. https://clincancerres.aacrjournals.org/ content/22/3/680.short.

85. Yang JC, Rosenberg SA. Adoptive T cell therapy for cancer. Elsevier; 2016. p. 279-94.

86. Rosenberg SA, Restifo NP. Adoptive cell transfer as personalized immunotherapy for human cancer. Science. 2015;348(6230):62-8. https://doi.org/10. 1126/science.aaa4967.

87. Baruch EN, Berg AL, Besser MJ, Schachter J, Markel G. Adoptive T cell therapy: an overview of obstacles and opportunities. Cancer. 2017;123(S11):2154-62. https://doi.org/10.1002/cncr.30491.

88. Farkona S, Diamandis EP, Blasutig IM. Cancer immunotherapy: the beginning of the end of cancer? BMC Med. 2016;14(1):73. https://doi.org/10. 1186/s12916-016-0623-5.

89. Morvan MG, Lanier LL. NK cells and cancer: you can teach innate cells new tricks. Nat Rev Cancer. 2016;16(1):7-19. https://doi.org/10.1038/nrc.2015. 5.

90. Rosenberg SA, et al. Use of tumor-infiltrating lymphocytes and interleukin-2 in the immunotherapy of patients with metastatic melanoma. N Engl J Med. 1988;319(25):1676-80. https://doi.org/10. 1056/NEJM198812223192527.

91. Hinrichs CS, Rosenberg SA. Exploiting the curative potential of adoptive $\mathrm{T}$ cell therapy for cancer. Immunol Rev. 2014;257(1):56-71. https://doi.org/ 10.1111/imr.12132.

92. Long GV et al. Epacadostat plus pembrolizumab versus placebo plus pembrolizumab in patients with unresectable or metastatic melanoma (ECHO-301/
KEYNOTE-252): a phase 3, randomised, double-blind study. Lancet Oncol 2019;20(8):1083-97 [Online]. Available: https://www.sciencedirect.com/science/ article/pii/S1470204519302748.

93. Melief CJM, van Hall T, Arens R, Ossendorp F, van der Burg SH. Therapeutic cancer vaccines. J Clin Invest. 2015;125(9):3401-12. https://doi.org/10. 1172/JCI80009.

94. Maverakis E, et al. Metastatic melanoma-a review of current and future treatment options. Acta Derm Venereol. 2015;95(5):516-24. https://doi.org/10. 2340/00015555-2035.

95. van der Burg SH, Arens R, Ossendorp F, van Hall T, Melief CJM. Vaccines for established cancer: overcoming the challenges posed by immune evasion. Nat Rev Cancer 2016;16(4):219-33 [Online]. https:// www.nature.com/articles/nrc.2016.16/boxes/bx2.

96. Johnson LA, et al. Gene therapy with human and mouse $\mathrm{T}$ cell receptors mediates cancer regression and targets normal tissues expressing cognate antigen. Blood. 2009;114(3):535-46. https://doi.org/10. 1182/blood-2009-03-211714.

97. Pestka S, Krause CD, Walter MR. Interferons, interferon-like cytokines, and their receptors. Immunol Rev. 2004;202(1):8-32. https://doi.org/10.1111/j. 0105-2896.2004.00204.x.

98. Parker BS, Rautela J, Hertzog PJ. Antitumour actions of interferons: implications for cancer therapy. Nat Rev Cancer 2016;16(3):131 [Online]. https://www. nature.com/articles/nrc.2016.14.pdf?origin=ppub.

99. Boyman O, Sprent J. The role of interleukin-2 during homeostasis and activation of the immune system. Nat Rev Immunol. 2012;12(3):180-90. https://doi.org/10.1038/nri3156.

100. Wargo JA, Reuben A, Cooper Z, Amaria R. Update on use of aldesleukin for treatment of high-risk metastatic melanoma. ImmunoTargets Ther. 2015. https://doi.org/10.2147/ITT.S61590.

101. Rehman H, Silk AW, Kane MP, Kaufman HL. Into the clinic: talimogene laherparepvec (T-VEC), a first-in-class intratumoral oncolytic viral therapy. J Immunother Cancer. 2016;4(1):53. https://doi. org/10.1186/s40425-016-0158-5.

102. Lipson EJ, et al. Safety and immunologic correlates of Melanoma GVAX, a GM-CSF secreting allogeneic melanoma cell vaccine administered in the adjuvant setting. J Transl Med. 2015;13(1):214. https:// doi.org/10.1186/s12967-015-0572-3.

103. Wong KK, Li WA, Mooney DJ, Dranoff G. Advances in therapeutic cancer vaccines. Elsevier; 2016. p. 191-249. 
104. Adusumilli PS, et al. New cancer immunotherapy agents in development: a report from an associated program of the 31st Annual Meeting of the Society for Immunotherapy of Cancer, 2016. J Immunother Cancer. 2017;5(1):50. https://doi.org/10.1186/ s40425-017-0253-2.

105. Tarazona R, Duran E, Solana R. Natural killer cell recognition of melanoma: new clues for a more effective immunotherapy. Front Immunol. 2016. https://doi.org/10.3389/fimmu.2015.00649.

106. Chester C, Ambulkar S, Kohrt HE. 4-1BB agonism: adding the accelerator to cancer immunotherapy. Cancer Immunol Immunother. 2016;65(10):1243-8. https://doi.org/10.1007/s00262-016-1829-2.

107. Salemi R et al. MMP-9 as a candidate marker of response to BRAF inhibitors in melanoma patients with BRAFV600E mutation detected in circulatingfree DNA. Front Pharmacol 2018;9:856 [Online]. https://www.frontiersin.org/articles/10.3389/fphar. 2018.00856/full.

108. Eskiocak B et al. Biomarker accessible and chemically addressable mechanistic subtypes of BRAF melanoma. Cancer Discov 2017;7(8):832-51 [Online]. https://cancerdiscovery.aacrjournals.org/content/7/ 8/832.abstract.

109. Larkin J, et al. Combined nivolumab and ipilimumab or monotherapy in untreated melanoma. N Engl J Med. 2015;373(1):23-34. https://doi.org/ 10.1056/NEJMoa1504030.

110. Gajewski TF, Louahed J, Brichard VG. Gene signature in melanoma associated with clinical activity: a potential clue to unlock cancer immunotherapy. Cancer J 2010;16(4):399-403 [Online]. https:// journals.lww.com/journalppo/fulltext/2010/07000/ Gene_Signature_in_Melanoma_Associated_With.17. aspx.

111. Ji R-R, et al. An immune-active tumor microenvironment favors clinical response to ipilimumab. Cancer Immunol Immunother. 2012;61(7): 1019-31. https://doi.org/10.1007/s00262-011-11726.
112. Harlin $\mathrm{H}$, et al. Chemokine expression in melanoma metastases associated with $\mathrm{CD} 8+\mathrm{T}$ cell recruitment. Cancer Res. 2009;69(7):3077-85. https://doi. org/10.1158/0008-5472.CAN-08-2281.

113. Zaretsky JM, et al. Mutations associated with acquired resistance to PD-1 blockade in melanoma. N Engl J Med. 2016;375(9):819-29. https://doi.org/ 10.1056/NEJMoa1604958.

114. Spranger S, Bao R, Gajewski TF. Melanoma-intrinsic $\beta$-catenin signalling prevents anti-tumour immunity. Nature. 2015;523(7559):231-5. https://doi. org/10.1038/nature14404.

115. Liu D, et al. Integrative molecular and clinical modeling of clinical outcomes to PD1 blockade in patients with metastatic melanoma. Nat Med. 2019;25(12): 1916-27. https://doi.org/10.1038/s41591-019-0654-5.

116. Tuaeva, et al. Translational application of circulating DNA in oncology: review of the last decades achievements. Cells. 2019;8(10):1251. https://doi. org/10.3390/cells8101251.

117. Lee EY, Kulkarni RP. Circulating biomarkers predictive of tumor response to cancer immunotherapy. Expert Rev Mol Diagn. 2019;19(10):895-904. https://doi.org/10.1080/14737159.2019.1659728.

118. Napoli S, et al. Functional roles of matrix metalloproteinases and their inhibitors in melanoma. Cells. 2020;9(5):1151. https://doi.org/10.3390/cells9051151.

119. Falzone L, et al. MMP-9 overexpression is associated with intragenic hypermethylation of MMP9 gene in melanoma. Aging (Albany NY). 2016;8(5):933-44. https://doi.org/10.18632/aging.100951.

120. Moogk D, et al. Melanoma expression of matrix metalloproteinase-23 is associated with blunted tumor immunity and poor responses to immunotherapy. J Transl Med. 2014;12(1):342. https://doi.org/10.1186/s12967-014-0342-7. 